\title{
Measuring Success Factors of Local Employee Management in Slovakia and Bulgaria
}

\author{
Hideki Takei \\ Dept. of Information Technology \& Administrative Management \\ Central Washington University \\ 400 E. University Way, Ellensburg, WA, USA
}

Tel: 1-509-963-2617_E-mail: takeih@cwu.edu

\begin{abstract}
There have been various researches for managers to make post-FDI operations successful. Areas of such researches include corporate governance, marketing, financing, production, distribution and logistics, supply chain management and human resource management (HRM). However, generally speaking, managers should focus on establishing effective organizations at the beginning of the post-FDI operations. Particularly, since FDI brings a high level of cultural diversity into organizations, knowing how to deal with local employees will be critical for expatriates as managers.

This research focuses on finding implications for manages to establish good labor relations with Slovak and Bulgarian employees in the post-FDI operations. This is important for managers because (1) FDIs in these countries have increased continuously and (2) local employees in the two nations have been familiar with foreign style management in somehow someway. Our goals are (1) to find opinions of local employees in Slovakia and Bulgaria and (2) to make several suggestions for managers to create better labor relations with the local employees.
\end{abstract}

Keywords: Human Resource Management, Foreign Direct Investment, Central Europe 


\section{Introduction}

There have been various researches for managers to make post-FDI operations successful. Areas of such researches include corporate governance, marketing, financing, production, distribution and logistics, supply chain management and human resource management (HRM). However, generally speaking, managers should focus on establishing effective organizations at the beginning of the post-FDI operations. Particularly, since FDI brings a high level of cultural diversity into organizations, knowing how to deal with local employees will be critical for expatriates as managers.

This research focuses on finding implications for manages to establish good labor relations with Slovak and Bulgarian employees in the post-FDI operations. This is important even if there are a few surveys finding some implications in these countries for two reasons. First reason is that FDIs in these countries have increased continuously. Second reason is that local employees in the two nations have been familiar with foreign style management in somehow someway. This means that they may have changed some cultural values in management by now.

Therefore, our first goal is to find opinions of local employees in Slovakia and Bulgaria so that we may find differences from results of previous studies. Then, our second goal is to make several suggestions for managers to create better labor relations with the local employees.

\section{Literature Review}

Study for human resource treatment in the Central and Eastern Europe has begun as cross-cultural study of human behaviors. These studies have tried to classify local cultures into several cultural dimensions to find specific characteristics of local human behaviors.

Luthans (1995) tried to classify cultural values of Czechoslovakia and CIS (former Soviet Union) into specific dimensions by Trompenaars's five cultural dimensions. These five cultural dimensions were respectively called as universalism/particularism, individualism/collectivism, achievement/ascription, neutral/affective, and specific/diffuse.

He rejected some of the general beliefs of the local cultures. For example, Czechoslovak culture showed strong preference to universalism while particularism had been considered as a common cultural dimension of the Central and Eastern Europe (Luthans, 1995). This indicated that Czechoslovak employees thought that clear rules and formal structures should be applied to make organizations more effective. Kennedy and Sandler (1997) looked for their explanations about this Luthan's finding in country-specific reasons such as early establishment of advanced business codes in Czech Republic prior to the socialistic revolution making Czechoslovakia.

It seems like there are two implications from this findings. First, Czechoslovak employees prefer transparency of control structure with established rules and fairness in organizations. Second, in order to strengthen such control structure, the employees think law and other enforcements must control the formal business codes. These implications look like interesting 
contrasts to CIS's cultural preferences to personal and informal relationships and rules based on mutual trust (Elenkov, 1998; Luthans, 1995).

Czechoslovakia's another contrast to CIS is their preference to individualism. This suggested that Czechoslovak employees' preference to clear personal responsibility, authority, and rewards rather than joint responsibility and group rewards in organizations.

Based on these results, one may consider more Anglo-American management style for Czechoslovak employees. However, this can be a very risky idea because we cannot universalize management style in where significant cultural and historical dependences exist. For example, Czechoslovak showed neutral positions in three other cultural dimensions. This means that they may accept a mixture of individual performances and birthrights as sources of positions, power, and earnings. They might not show strong emotions publicly while they did show emotions but less openly. Since they needed to balance between specific and diffuse dimensions, they might be detached in public and friendly for insiders while they still kept large public space. These results showed neither contractarian style (Anglo-American style) nor Communitarian style would be perfectly appropriate for Czechoslovakia (Elenkov, 1998; Luthans, 1995).

There are also various cultural dimensions in the Central and Eastern Europe to find potential success factors in human resource treatments. Managers could mislead local organizations by treating human resources in inappropriate ways if they blindly control and organize local employees with the generally accepted principles in the dimensions. These studies also discussed risks for managers to find a universal management style which fits in everywhere in the Central and Eastern Europe (Elenkov, 1998; Luthans, 1995).

Cyr (1996) found various success factors for managers to create effective learning organizations and international joint ventures in Poland, Hungary and Czech Republic. This study indicated local employees' strong desire to learn new skills, to demonstrate their competence and to earn enough compensation to catch up with the Western living standard. Therefore, we could say ignoring these desires would seriously de-motivate the local employees in active learning and cooperation. His study also implied the needs for managers' constant interests, attentions and supports to their learning activities, learning levels, performances, processes and systems of performance appraisals and compensations (Cyr, 1996).

In order to maintain both local employees' motivation and attentions from their managers, Cyr (1996) suggested frequent two-way communications and interactions with the local employees. He also pointed that frequent two-way flows of communications would ensure effective knowledge transfer between expatriates and the local employees since the local employees want not only to gain new skills but also to show their competence through binary communications. The two-way communications between them would enable local employees to receive information about corporate visions, strategic directions, operational situations and other operational information from the managers.

After all, information sharing via two-way communications would develop mutual trust between managers and local employees so that managers could lead local employees towards common goals. Naturally, managers should not forget appropriate incentives in order to 
motivate local employees continuously. According to Cyr (1996), such incentives can be mainly economic rewarding; however, recognitions and awards in organizations are also equally important.

Cyr's points were supported by another study by Marshall (1999) in the Central and Eastern Europe. According to Marshall (1999), effective communications was one of the most critical success factors. He found three communication-related problems that would be serious obstacles for establishing effective organization.

The first problem is that local employees' tendency of hesitation to ask for help in a timely manner. They usually waited until managers noticed problems and offered supports. Marshall (1999) considered that this passive attitude might be caused by very frequent top-to-down communications in Central and Eastern European organizations. In order to improve this situation, he suggested two-way communications in organizations because top-to-down flows enabled managers to notice their subordinates' needs for help when bottom-to-up flows enabled local employees to ask superiors for supports. Similar to Cyr's arguments, (Cyr, 1996), Marshall (1999) pointed out the importance of incentives and encouragement to the local employees for active participations in the two-way communications flows.

The second problem is slower speed of decisions makings by local employees. According to Marshall (1999), this might be caused by poor information sharing and exchanges to establish strong consensus among the decision makers and participants. Poor information sharing and exchanges could be worsened with time-consuming establishment of enough personal relationship and mutual trust to secure frequent information exchange and sharing. In addition to it, close personal relationships might cause other organizational problems such as self-dealing problems during decision-making and strong tolerance to poor performances in operations. Therefore, mutual trust, transparency of information and clear information flows have to be ensured throughout the binary information flows.

The last problem is a generation gap that creates serious conflicts between senior and younger local employees in organizations. According to Marshall (1999), the senior generation is ignoring environmental changes and new ways of doing while the younger generation is demanding unrealistically high treatments and compensations from companies. The two-way and frequent information exchanges and interactions are considered as necessary to solve this problem.

Kiriazov et al (2000) and Lipiec (2001) suggested three success factors to create effective organizations based on their studies of HRM in the Central and Eastern Europe. According to Kiriazov et al (2000), the three factors are respectively (1) focusing on extrinsic rewards such as money and fringe benefits, (2) building mutual trust to eliminate doubts on fairness in organizations, and (3) being patient for slow changes, decisions and learning.

Lipiec (2001) added further discussions on the second success factor. According to Lipiec, in order to ensure fairness in organizations, we will need fair performance appraisal and rewards, clear structures and rules, disclosure and information sharing, mutual trust, and two-way communications. The fair performance appraisal includes structured performance-based appraisal systems, explicit rewards, and timely feedback and recognitions from superiors. 
Mayrhofer and Brewster (2004) reported that a number of corporations in Europe have already introduced such structured performance-based appraisal system.

We summarized findings and suggestions from various studies. Our summary here will be compared to results of our own study in order to find mentality of local employees in Slovakia and Bulgaria and to make several suggestions for managers to create better labor relations with the local employees.

Our steps to develop general success factors based on various empirical studies are described as follows. The first step is to summarize results of each study. The second step is to summarize implications and suggestions from each study. The third step is to create the grounds for an argument of the general success factors by re-summarizing items on the previous two steps. The last step is to hypothesize the general success factors of human treatments of local employees in the Central and Eastern Europe.

Our hypothesized general success factors showed four principles that managers should respect for better human treatments and, therefore, organizational effectiveness in the Central and Eastern Europe. First principle is frequent binary communications with the subordinates to show their supports and recognitions. When managers see dissatisfactions and frustrations of the local employees, they should deal with by systematic and fair procedures within clear formal structures and rules.

Second principle is mutual trust with the local employees through two-way and frequent communications and disclosures. Such communications and disclosures should be done within the transparent structures to minimize possibility of serious self-dealing problems.

Third principle is consensus-based decision-making through efficient information sharing and binary communication flows. Such consensus-based decision-making also improve accountabilities of local employees because understanding (1) process of the decision-making, (2) contents and values of the decision, (3) tasks and responsibility, and (4) directions and goals of the decision will let the local employees get together and move towards particular organizational goals.

Forth principle is fair rules and treatments in organizations and systems. Particularly, fairness in performance appraisals and rewards would be important in order to maintain fairness among employees. Local employees of the Central and Eastern Europe tend to be very sensitive to nepotism in organizations.

We developed five suggestions that managers should respect and these suggestions were compared with our collected data in Slovakia and Bulgaria. The five suggestions are respectively (1) cares, understandings and recognitions, (2) frequent and 2-way communications, (3) disclosure, transparency and information sharing, (4) fairness, clear structures and rules and (5) fair performance appraisals and rewards.

\section{Methodology}

Our questionnaire had four open-end questions which asked (1) problems causing operational and organizational inefficiency and (2) causes of the problems, characteristics of bad bosses 
and additional comments on the related issues. In addition to the questionnaire, we held open discussions with all participants after the questionnaire in order to clarify their answers and comments.

We distributed the questionnaire to local employees in Slovakia and Bulgaria. We had thirty middle to upper-middle level Slovak managers and four expatriates in two multinational companies. In Bulgaria, we had six middle to upper-middle level Bulgarian managers in six multinational enterprises. Origins of the companies were Japan and USA.

\section{Discussions}

I seemed like our general success factors were valid in these countries as Table 1 and figure 1 showed. While our results seemed to be similar to the results of previous studies, it was important for us to check our results with our five suggestions in order to ensure consequence to our discussions. After we checked with the suggestions, we estimated importance of each factor based on numbers of comments and answers expressing the factor directly or indirectly. Figure 1 show the importance and its level of significance in the two nations.

In Slovakia, there were three distinctive success factors that consisted of approximately $90 \%$ of all valid answers and comments. These factors were respectively (1) fairness and clear structures and rules, (2) frequent and two-way communications, and (3) disclosure, transparency and information sharing. In Bulgaria, there were three distinctive success factors that consisted of approximately $80 \%$ of all valid answers and comments. These factors were respectively (1) fairness and clear structures and rules, (2) cares, understandings and recognitions, and (3) frequent and two-way communications.

While our results in the two countries showed very similar factors, we noticed differences in the level of importance of each factor. For example, our data showed different level of important of "cares, understandings and recognitions." While only 3\% of Slovak participants thought the factor was important, 20\% of Bulgarian participants considered as important.

Our open discussions with Bulgarian participants told they thought self-esteem and job satisfaction had to be well maintained in their organizations. It seemed like self-esteem and job satisfaction were created and kept when they felt prides, status, and feels of achievement and contribution in their jobs and organizations. In addition, they told us that their job satisfactions had to come from not only monetary compensations but also non-monetary rewards such as positions, titles, reputations, formal recognitions and respects in their organizations. Several Bulgarian employees expressed their respect to seniority-based and lifetime employment system because they could see better job security and career path in the system.

We found that Slovak employees seemed to be more individualistic. They seemed to value clear structures and rules of human treatments and evaluations in order to ensure fairness in organizations. This respect to fairness could be seen when they considered information sharing and frequent two-way communications as the foundations for better and fair job performance. They also expected that performance appraisal feedback had to be communicated and disclosed in a timely manner for fair compensations and treatments. 


\section{Conclusion}

It seemed that there was no particular difference between our data and our general success factors in the Central and Eastern Europe. However, when we checked importance of each factor, it seemed like there was a possible emergence of divergence from the general success factors. This means that, while the general success factors are still valid in Bulgaria and Slovakia, we need to apply the success factors with different propriety and balance. In other words, it has been inappropriate for researchers and managers to look at the Central and Eastern Europe as a large region. We do need to rather see each country in the region for better organizational effectiveness.

\section{References}

Cyr, Dianne J. (1996). Implications for learning: human resources management in East-West joint ventures - Special Issues on Managerial Learning in the Transformation of Eastern Europe. Organizational Studies, 17(2), 207-26.

Elenkov, Detelin S. (1998). Can American Management Concepts Work in Russia? A Cross-Cultural Comparative Study. California Management Review, 40 (4).

Kennedy, Robert., \& Sandler, Amy. (1999). Shock Therapy in Eastern Europe: The Polish and Czechoslovak Economic Reforms. Harvard Business School Case.

Kiriazov, Dimiter., Sullivan, Sherry E., \& Tu, Howard S. (2000). Business Success in Eastern Europe: Understanding and Customizing HRM. Business Horizons, 43, 39-43.

Lipiec, Jacek. (2001). Human resource management perspective at the turn of the century. Public Personnel Management,30 (2), 137-146.

Luthans, Fred. (1995). Doing business in Central and Eastern Europe: political, economic, and cultural diversity. Business Horizons, 38, 9-16.

Marshall, Jeffrey. (1999). Communicating in Eastern Europe. Harvard Management Communication Letter.

Mayrhofer, Wolfgang., \& Brewster, Chris. (2004). European Human Resource Management: Researching Developments Over Time. [Online] Available: http://findarticles.com/p/articles/mi_qa5454/is_200501/ai_n21369360/ (February, 2011). 


\section{Appendix}

\section{Appendix 1.}

Table 1. Summary of our result

\begin{tabular}{|c|c|}
\hline Problems(Slovakia) & $\begin{array}{l}\text { Poor communication about corporate policies and strategic directions. } \\
\text { One-way communication (Top-to-down communication) flow. } \\
\text { Unstructured inform from superiors. } \\
\text { Poor feedback from superiors. } \\
\text { Poor consensus (Somebody’s business syndrome). } \\
\text { Insufficient information to do work and make decisions. } \\
\text { Ineffective meeting (no problem solving, blaming on each other, no } \\
\text { accountabilities of participants). } \\
\text { Unclear and unfair performance appraisal and feedback. } \\
\text { Unclear and unfair performance appraisal and feedback. } \\
\text { Unclear task and responsibility. } \\
\text { Poor monitoring and supervisions. } \\
\text { Poor coaching and supporting for problem solving. } \\
\text { Slow and untimely executions. } \\
\text { Poor initiatives, passive attitudes of employees. } \\
\text { No suggestions. } \\
\text { Weak participants. } \\
\text { Self-dealing, defending own interests. }\end{array}$ \\
\hline Problems(Bulgaria) & $\begin{array}{l}\text { Poor recognition(less attentions, no titles). } \\
\text { Unclear career path. } \\
\text { Unfair performance appraisal. } \\
\text { Free-riding. } \\
\text { Poor information disclosure and sharing. } \\
\text { One-way communication (Top-to-down communication) flow. } \\
\text { Less participation. } \\
\text { Poor and business-little human relations. } \\
\text { Unfair rewards and treatment (Poor job satisfaction due to unfair rewards). } \\
\text { Personal preference and interests (Self-dealing). } \\
\text { Personal relationship (Unfairness). } \\
\text { Pressure from the top. } \\
\text { No incentives for improvement and suggestions. } \\
\text { "Do-me-a-favor syndrome”. } \\
\text { "I close my eyes for my friends' mistakes and self-dealings" } \\
\text { Huge tolerance to poor performance of "friends". } \\
\text { Reactive and passive attitudes. } \\
\text { “Me-too and Why-me syndromes". } \\
\text { Unclear rules and structure. }\end{array}$ \\
\hline Problems(Bosses) & $\begin{array}{l}\text { Make unclear decisions. } \\
\text { Negative attitudes (keep rejecting, disagreeing, stressing). } \\
\text { Moody. } \\
\text { Unfair. } \\
\text { Arrogant. }\end{array}$ \\
\hline
\end{tabular}




\section{Macrothink}

Research in Applied Economics

ISSN 1948-5433

2011, Vol. 3, No. 1: E5

Appendix 2.

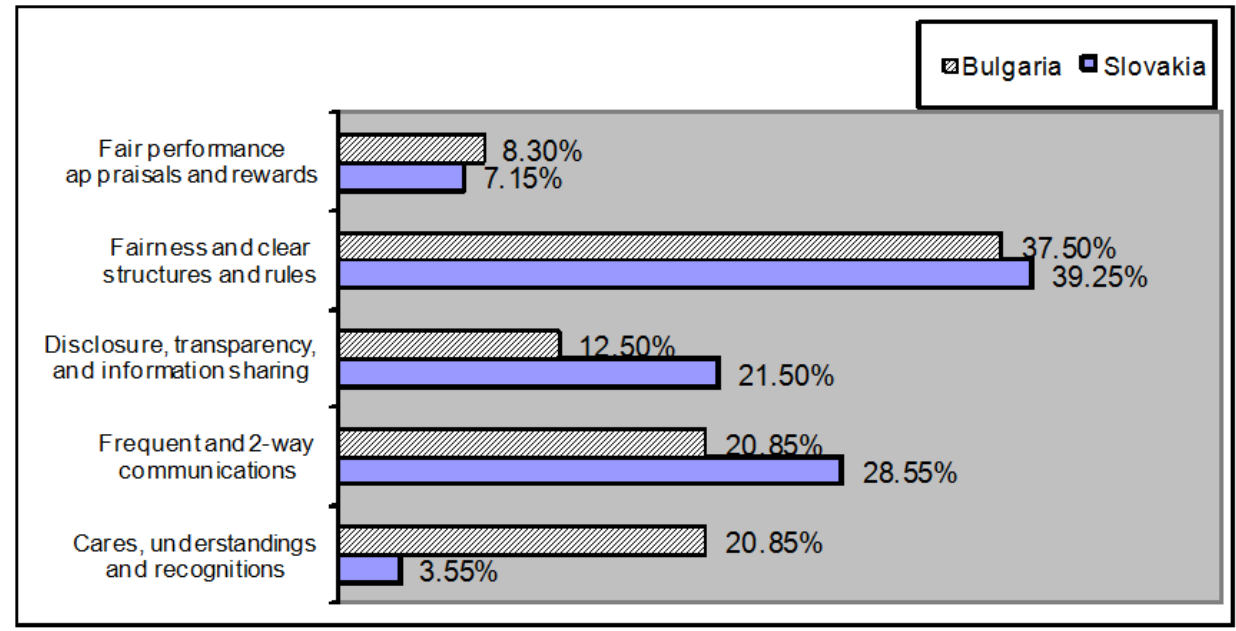

Figure 1. Results of our study and importance

\section{Copyright Disclaimer}

Copyright reserved by the author(s).

This article is an open-access article distributed under the terms and conditions of the Creative Commons Attribution license (http://creativecommons.org/licenses/by/3.0/). 